\title{
Students' and Teachers' Perceptions of Factors Leading to Poor Clinical Skill Development in Medical Education: A Descriptive Study
}

\author{
Chatterjee Nandini, ${ }^{1}$ Das Suvajit, ${ }^{2}$ Mukhopadhyay Kaushik, ${ }^{2}$ and Chatterjee Chandan ${ }^{2}$ \\ ${ }^{1}$ Department of Medicine, NRS Medical College, KolKata 700014, India \\ ${ }^{2}$ Department of Pharmacology, ESI-PGIMSR, ESIC Medical College, Kolkata 7000104, India \\ Correspondence should be addressed to Chatterjee Nandini; soriasis_2009@yahoo.in
}

Received 21 June 2015; Revised 2 October 2015; Accepted 25 October 2015

Academic Editor: Connie M. Wiskin

Copyright (C) 2015 Chatterjee Nandini et al. This is an open access article distributed under the Creative Commons Attribution License, which permits unrestricted use, distribution, and reproduction in any medium, provided the original work is properly cited.

\begin{abstract}
Background. Our study was taken up to explore the possible factors influencing poor performance of undergraduate students in clinical skill demonstration. Aims. Identification of factors leading to poor clinical skill development in undergraduate medical students. Settings and Design. This is an observational study. Methods and Material. The study population comprised the undergraduate students and teachers of the Department of Medicine. All were provided with structured questionnaires who responded anonymously which were then interpreted with the help of software statistical calculator. Results. Of the 145 students, only 57 (39.3\%) actually attended medicine ward. The major factors that the students reported were large groups of students around a patient $(94.74 \% \pm 4.67)$, inadequacy of information in books of clinical medicine $(78.9 \% \pm 8.53)$, overcrowded unclean wards $(73.7 \% \pm 9.2)$, lack of practice of clinical methods at home $(50.8 \% \pm 10.4)$, and timing of classes $(42.1 \% \pm 10.3)$. Teachers cited poor attendance of students to wards $(76.2 \% \pm 17.1)$, poor condition of wards and lack of separate enclosures to teach (100\%), and large groups around a single patient $(66.67 \% \pm 17.9)$. Conclusions. Absenteeism of students, overcrowding of wards, and lack of uniformity of study materials were prime factors.
\end{abstract}

\section{Introduction}

Clinical medicine seems to have taken a back seat nowadays. With the advent of newer, more sophisticated investigations, our dependence on clinical examination is gradually diminishing. This trend seems to be percolating into the students' community as well. It is a well perceived fact that present day undergraduate students are relatively weaker in clinical skill development in sharp contrast to their theoretical knowledge. Whether this is due to lacunae in the existing clinical teaching learning process is not known. An Australian cross sectional study with 152 teachers reported bedside clinics as an effective means of teaching but cited noisy ward, time constraint, and lack of patient as probable hindrances [1]. Another western study among final year students found greater confidence in physical examination in Dominican Republic students than American students [2].
According to a study from Delhi in 2003, learner absenteeism was directly connected with poor achievement while low achievers were chronically absent [3]. Sadly such reflective works are conspicuous by their absence in our large country. Therefore this study was taken up to throw some light on the students' perspective as well as teachers' point of view regarding bedside teaching.

\section{Objective}

Identification of factors leading to poor clinical skill development in undergraduate medical students.

\section{Subjects and Methods}

This observational descriptive study was carried out in the Department of Medicine, in NRS Medical College, for 
duration of 3 months. The study population comprised the undergraduate students of 8th-9th semester who attended wards during that period and teachers of the department of medicine. All were provided with structured questionnaires (separate for each group). Both the students and teachers responded anonymously to the questionnaires which were then interpreted with the help of appropriate statistical tools. The 21 teachers of the department were divided into two groups A and B. Group A had teaching experience less than 10 years, while group $B$ had experience greater than 10 years. This was done to find out whether there was any significant difference of opinion among the senior and junior teachers on similar issues using the Fischer's Exact test (software statistical calculator).

Positive and negative responses in the questionnaires were expressed as percentages of the total and arranged in descending order. The major unfavorable factors leading to poor clinical skill development were unearthed.

\section{Results}

The total number of students in the batch was 145 (124 males, $85.6 \%$, and 21 females, $14.4 \%) .110$ students (76\%) were hostelites while only 35 (24\%) were day-scholars. Within that 3-month study period, all 145 students were scheduled to attend wards (Batch A, July, Batch B, August, and Batch C, September). The timing of clinics was from $9 \mathrm{am}$ to 12 oclock and officially each patient was allotted to a group of 10 students.

Of the 145 allotted students, only fifty seven students were found in the wards to fill up the questionnaires. Hence around 39.3 regularly attended ward clinics while others were absent. Forty seven were male (83\%) and ten female (17\%) Moreover, of those who attended wards, 47 students were hostelites (83\%), while the rest were day-scholars. The male to female and hostelites ratios of those who attended wards were comparable to those of the study population (8th-9th semester batch).

The major unfavorable factors that the students agreed upon were (Table 2)

(1) large groups of students around a single patient, $94.74 \% \pm 4.67$

(2) inadequacy of information in books of clinical medicine, $78.9 \% \pm 8.53$,

(3) overcrowded unclean wards, $73.7 \% \pm 9.2$,

(4) lack of practice of clinical methods at home, $50.8 \% \pm 10.4$

(5) timing of classes, $42.1 \% \pm 10.3$.

Students attributed their poor clinical performance to these factors. However, they conceded that there was a large variety of cases in our hospital and most patients cooperate while being examined.

According to teachers the principle unfavorable factors were (Table 1)

(1) poor attendance of students to wards, $76.2 \% \pm 17.1$,
TABLE 1: Responses of teachers.

\begin{tabular}{lcc}
\hline Question number & Yes\% & No\% \\
\hline Q1 & $23.8 \pm 16.17$ & $76.2 \pm 16.17$ \\
Q2 & $33.33 \pm 17.9$ & $66.66 \pm 17.9$ \\
Q3 & $95.2 \pm 8.13$ & $4.8 \pm 8.13$ \\
Q4 & 100 & 0 \\
Q5 & $85.7 \pm 13.3$ & $14.3 \pm 13.3$ \\
Q6 & $38.1 \pm 18.44$ & $61.1 \pm 18.44$ \\
Q7 & - & - \\
Q8 & $90.5 \pm 11.14$ & $9.5 \pm 11.14$ \\
Q9 & $61.9 \pm 18.4$ & $38.1 \pm 18.4$ \\
\hline
\end{tabular}

TABLE 2: Responses of students.

\begin{tabular}{lccc}
\hline Question number & Yes\% & No\% & To some extent \\
\hline Q1 & $88 \pm 6.79$ & $3.5 \pm 3.84$ & $8.5 \pm 5.83$ \\
Q2 & $38.6 \pm 10.17$ & $42.1 \pm 10.31$ & $19.3 \pm 8.24$ \\
Q3 & $94.74 \pm 4.67$ & 0 & $5.25 \pm 4.66$ \\
Q4 & $43.86 \pm 10.37$ & $5.4 \pm 4.7$ & $50.8 \pm 10.4$ \\
Q5 & $21 \pm 8.51$ & $50.8 \pm 10.44$ & $28.2 \pm 9.4$ \\
Q6 & $3.6 \pm 3.8$ & $78.9 \pm 8.53$ & $27.6 \pm 9.34$ \\
Q7 & $73.7 \pm 9.2$ & $12.3 \pm 6.87$ & $14 \pm 7.25$ \\
Q8 & $45.6 \pm 10.4$ & $3.5 \pm 3.8$ & $51 \pm 10.44$ \\
Q9 & $82.4 \pm 7.9$ & $10.5 \pm 6.4$ & $7 \pm 5.33$ \\
\hline
\end{tabular}

(2) poor condition of wards and lack of separate enclosures to teach $100 \%$,

(3) large groups around a single patient (students tend to crowd in the classes of favorite teachers only), $66.67 \% \pm 17.9$.

The teachers find the time of clinical classes convenient and there is a large variety of cases to be taught.

There was no significant difference of opinion between teachers of groups A and B.

\section{Discussion}

The most remarkable finding in this study was the miserable attendance (39.3\%) of the students to the wards. The teachers unanimously agreed that this was the single most important factor leading to poor clinical skill development in our students. Handling patients in the wards and observing clinical methods being demonstrated by the teachers are vital in learning clinics. According to a study from Delhi in 2003, learner absenteeism was directly connected with poor achievement while low achievers were chronically absent [3]. The author stresses on counseling by support groups of family, peer, faculty, and psychologist to counter absenteeism.

The students cited large groups (20-25) around a teacher as a hindrance to proper learning. Though the administration had divided students 
in groups of ten, they tend to accumulate in the groups of their favorite teachers. They (students) opine that there is lack of uniformity in teaching standards and even suggest periodical assessment of teachers' scholastic prowess as well.

Unclean, overcrowded wards, a constant feature in our setup, have been pointed out by both the students and teachers as a major distraction. This view has been echoed in the works of others as well [1].

Notably, books on clinical methods (i.e., Macleod's Textbook of Clinical Medicine, Hutchison's Textbook of Clinical Medicine) have been blamed for being incomplete and contradictory. In a novel study in UK, the authors reviewed routinely available texts of clinical musculoskeletal examination and concluded that the current texts available to medical students and junior doctors do not provide sufficient information regarding the assessment of patients [4].

Students also agree that lack of practice on their part and at times inability to fully grasp the lessons lead to problems. According to a study in California, poor performance in comprehensive assessments often indicates underlying deficiencies in cognitive ability, communication skills, or professionalism. The challenge of remediating these deficiencies late in medical school calls for earlier identification and intervention [5]. However the students only are not to be blamed. One Californian study found that the teachers had modest confidence in remediating clinical skill deficiency of 4 th year students [6].

A lot of work in the Western world is being aimed at improving this state of affairs. It is well documented that better clinical evaluation methods are to be designed for the betterment of poor performance [7]. Practice based learning exercises that incorporated feedback to students may hold the key to the deadlock [8].

The importance of valid and reliable assessment of student competence and performance is gaining increased recognition. A formative assessment tool that reliably predicts performance in the summative setting would be of value to both students and teachers. In this context the utility of the team objective structured bedside assessment (TOSBA), a novel ward-based formative assessment tool in predicting student performance in the final clinical examination has been brought to notice. In a particular study web-based video clips, consisting of instruction in 77 elements of the physical examination, were created using Microsoft Windows Moviemaker software. A significant improvement in medical student performance occurred after implementing webbased instructional video [9]. Such facilities are a distant dream for our students, and there is no harm in hoping that web-based clinical learning will be part of the curriculum in the days to come.

A prospective means of curtailing absenteeism can be a mandatory minimum $75 \%$ attendance for a student to sit for the final examination.

Our study suffers from certain limitations. Sample size was too small and also nonresponse rate was found too high. Multivariate logistic regression would have been the better statistical test of significance.

\section{Conclusion}

Factors for poor clinical skill development are manifold and complex. Absenteeism of students from wards is a prime factor. Others include unfavourable ambience of the wards, too many students around a single teacher, and lack of uniformity of study materials. Minor issues include inadequate practice of clinical methods and timing of classes. However further work is needed to unearth the reasons for absenteeism of students, which holds the key to a possible solution to this problem.

\section{Conflict of Interests}

There is no conflict of interests in this study.

\section{References}

[1] B. R. Nair, J. L. Coughlan, and M. J. Hensley, "Impediments to bed-side teaching," Medical Education, vol. 32, no. 2, pp. 159162, 2002.

[2] M. Fagan and E. Wu, "Attitude towards physical examinationAmerican and Dominican Republic students," Teaching and learning in Medicine, vol. 18, pp. 287-291, 2006.

[3] U. Dhaliwal, "Absenteeism and under-achievement in final year medical students," National Medical Journal of India, vol. 16, no. 1, pp. 34-37, 2003.

[4] L. J. Kay, D. A. Coady, and D. J. Walker, "Joints: If relevant. Do available textbooks contain adequate information about musculoskeletal examination skills for medical students?" Medical Teacher, vol. 23, no. 6, pp. 585-590, 2001.

[5] K. E. Hauer, A. Teherani, K. M. Kerr, P. S. O'Sullivan, and D. M. Irby, "Student performance problems in medical school clinical skills assessments," Academic Medicine, vol. 82, no. 10, supplement, pp. S69-S72, 2007.

[6] V. Saxena, P. S. O’Sullivan, A. Teherani, D. M. Irby, and K. E. Hauer, "Remediation techniques for student performance problems after a comprehensive clinical skills assessment," Academic Medicine, vol. 84, no. 5, pp. 669-676, 2009.

[7] E. R. Petrusa, T. A. Blackwell, L. P. Rogers, C. Saydjari, S. Parcel, and J. C. Guckian, "An objective measure of clinical performance," The American Journal of Medicine, vol. 83, no. 1, pp. 34-42, 1987.

[8] M. Srinivasan, K. E. Hauer, C. Der-Martirosian, M. Wilkes, and N. Gesundheit, "Does feedback matter? Practice-based learning for medical students after a multi-institutional clinical performance examination," Medical Education, vol. 41, no. 9, pp. 857-865, 2007.

[9] S. D. W. Miller, M. W. Butler, F. Meagher, R. W. Costello, and N. G. McElvaney, "Team Objective Structured Bedside Assessment (TOSBA): a novel and feasible way of providing formative teaching and assessment," Medical Teacher, vol. 29, no. 2-3, pp. 156-159, 2007. 

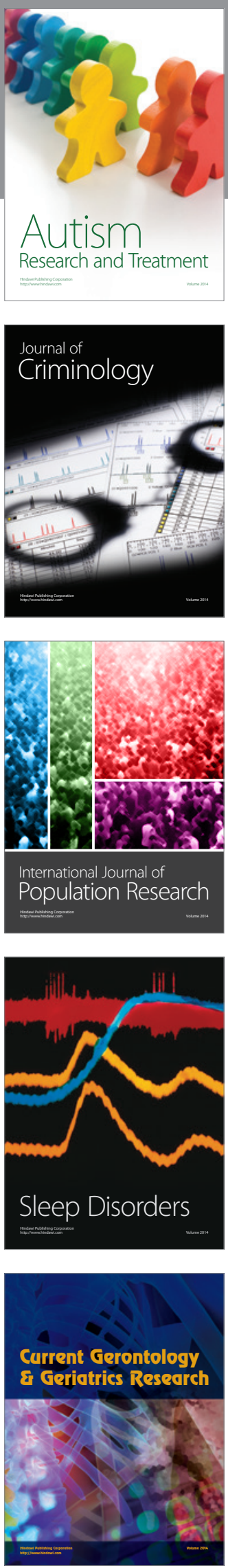
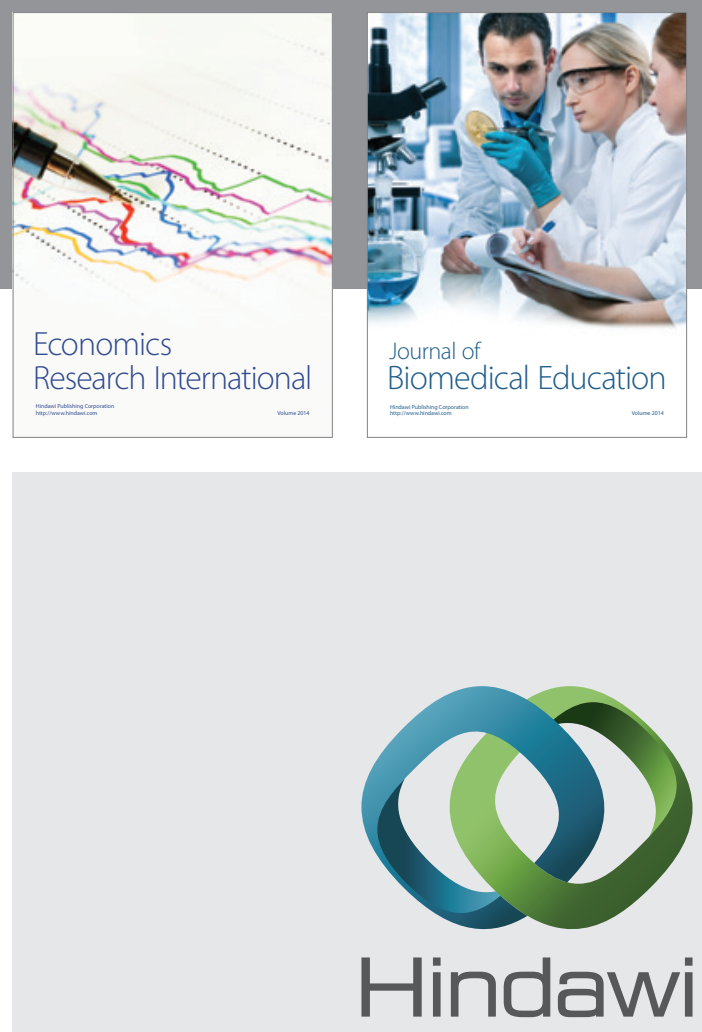

Submit your manuscripts at

http://www.hindawi.com
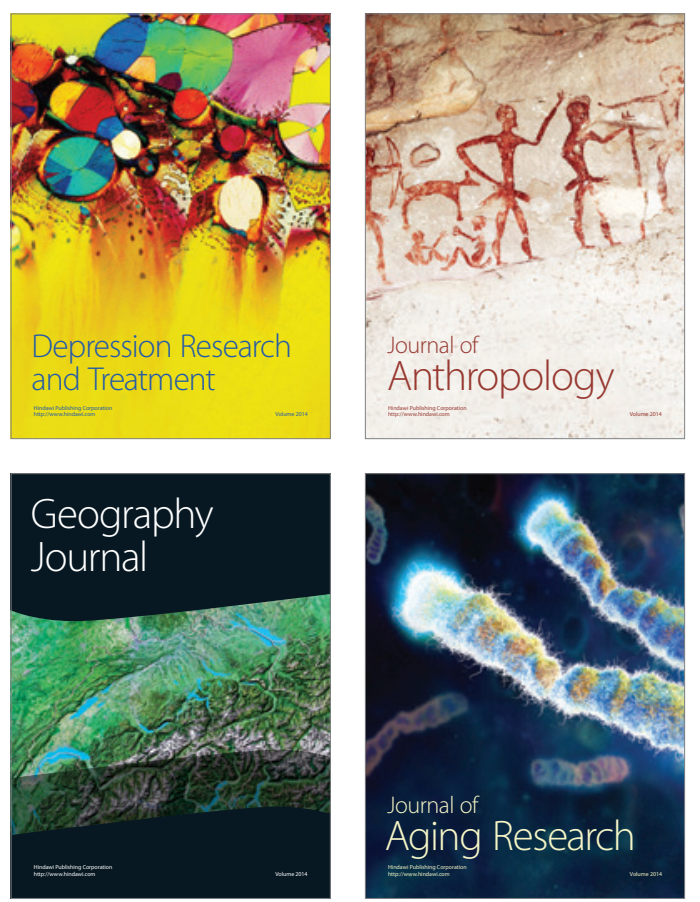
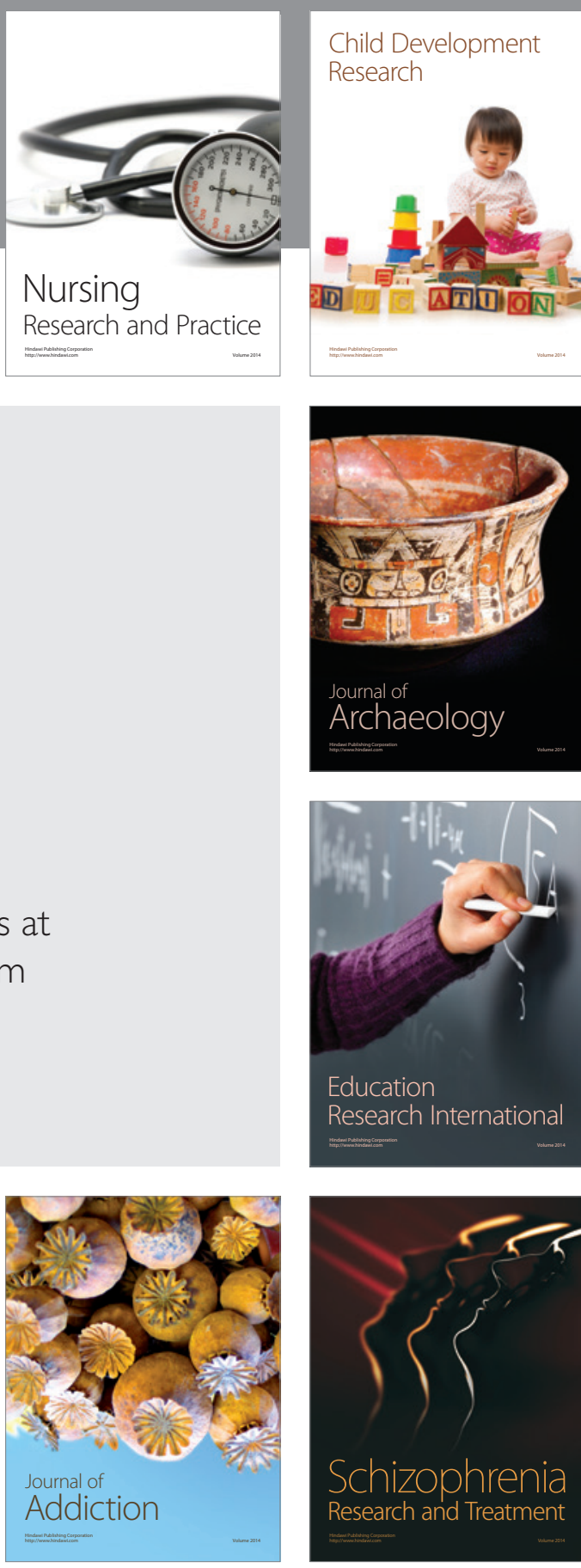

(D)
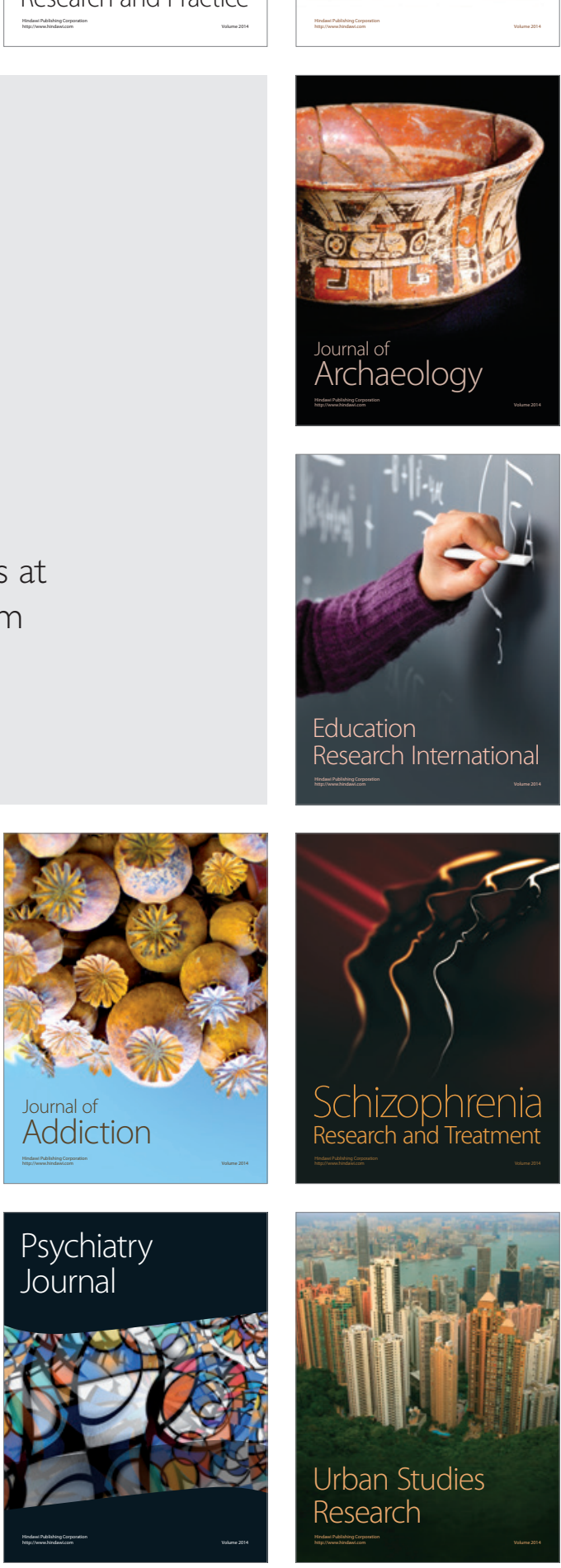